\title{
Thermodynamics of Small Electron-Bound Water Clusters
}

\author{
Sik Lee and Han Mỵoung Lee ${ }^{\dagger+*}$ \\ Center for Computational Biologv and Bioinformatics, Korea Institute of Science and Technologv Information. \\ Fuseong P.O. Box 122, Daejeon 305-600, Korea \\ -Center for Superfunctional Materials. Department of Chemistry. Pohang Lnivensitv of \\ Science and Technologv. Pohang 790-784, Korea \\ Recened April 24, 2003
}

\begin{abstract}
The relative stabilities of weak binding clusters are sensitive to temperature due to the entropy effect. Thus. here we report significant changes in relative stabilities between two low-energy electron-water trimer stnictures and those between three low-energy electron-water pentamer structures. as the temperature increases. The trimer and pentamer show stnictural changes around $200 \mathrm{~K}$.
\end{abstract}

Key Words : Solvated electron. Electron-bound water cluster, Electron-water clusters. Thernodynanuics, Vertical-electron detachment energy

\section{Introduction}

As water is the most important solvent. the electron-water clusters have been an interesting subject in physics. chemistry and biochemistry. The formation of long-lived electron-water clusters $\left[e^{-}\left(\mathrm{H}_{2} \mathrm{O}\right)_{13}, \mathrm{n} \geq 11\right]$ was observed by electron attaclument to cold neutral water clusters.: Some electron-water clusters were obtained through the chargetransfer to water (CTTS: charge transfer to solvent) from anions such as halide ions.-7 Small electron-water clusters were observed by the time-of-flight mass. " infrared (IR) ${ }^{8-10}$ or Raman ${ }^{11}$ and photoelectron spectroscopic (PES) ${ }^{12}$ tools. These experiments provide $\mathrm{OH}$ or $\mathrm{OD}$ stretching IR frequencies and vertical-electron detachment energies (VDE). Based on these experimental results. many theoretical studies of electron-bound water clusters have been performed in order to obtain their structural and spectroscopic information with high level $a b$ initio theories. ${ }^{13-15}$ which are essential to investigate the properties due to very weak binding and diffuse excess electron. The structures, spectra and electronic properties of electron-water dimer to octaner were investigated and reported by using $a b$ initio calculations especially at the levels of Moller-Plesset second-order perturbation (MP2) and coupled cluster single and double excitations (CCSD) with the aug-cc-pVDZ $+(2 s 2 \mathrm{p} / 2 \mathrm{~s})$ basis set. ${ }^{15}$ The MP2 and CCSD calculations have shown realistic energetics. The Becke s three-parameter exchange and Lee-Yang-Parr correlation functionals (B3LYP) calculations have often been employed because they give reasonable IR spectroscopic data with minimal computation efforts. despite that the electronic properties such as VDEs are poorly evaluated. Thus, both calculation approaches have been widely used for neutral water. ${ }^{16}$ ion-water clusters. ${ }^{5,17} \pi$-water clusters ${ }^{18}$ and solvated or biological systems. ${ }^{15}$ The use of highly diffuse basis set for the electron-bound water clusters was essential to obtain reliable stabilities. speactra. and electronic properties of electron-water clusters.

Although many low-energy structures of electron-water clusters have been known at $0 \mathrm{~K}$. the structural changes depending in the temperature have not been reported. Since the relative stabilities of weak binding clusters are very sensitive to temperature due to the entropy effect. it is of importance to investigate the changes in relative stabilities for the electron-water clusters. Since two low-energy electronwater trimer structures have the cyclic and linear conformations. and three low-energy electron-water pentamer structures are known to have nearly same energies with different number of hydrogen bonds (HBs) ${ }^{15}$ we investigate the relative stabilities for these conformers depending on temperature. Indeed. as the temperature changes from $0 \mathrm{~K}$ to the room temperature. we find that the lowest energy structures have drastically changed.

\section{Calculation Methods}

Many structures and energetics of small electron-water clusters were calculated at the MP2/aug-cc-pVDZ+(2s $2 \mathrm{p} / 2 \mathrm{~s})$ levels of theory. ${ }^{15}$ These extra diffuse $\mathrm{sp}$ functions were added to all oxygen atoms in order to effectively bind the excess electron. All the exponents of the added diffuse basis functions in parentheses were scaled by the $1 / 8$ factor from those of each corresponding outermost basis function. The vibrational frequencies were used to evaluated zero-pointenergies (ZPEs) and thermodynamic quantities. The B3LYP ZPE corrections of electron-water cluster are known to give slightly smaller than the MP2 ones.

The dependency of basis set on stabilities and electronic properties of electron-bound water clusters was investigated in terms of the extra diffuse basis functions and polarization functions of d-orbitals of oxygen atoms and p-orbitals of hydrogen atoms. The MP2/aug-cc-pVDZ+(2s $2 \mathrm{p} / 2 \mathrm{~s})+\mathrm{X}(3 \mathrm{~s} 3 \mathrm{p})$ calculations with the smaller basis set calculations were performed for the electron-water trimer. The $X(3 \mathrm{~s} 3 \mathrm{p})$ basis set (the exponents of which are 0.01,0.00125 and 0.00015625 ) was used to evaluate the extra basis function effect on the relative stabilities and VDEs. Based on this stuffy. we note that the present basis set is very reliable for the present study. All calculations were carried out using a suite of Gaussian progranı ? $^{\text {? }}$ 


\section{Results and Discussion}

Many interesting conformers including internal-bound states for the electron-water trimer were reported for their relative energies and electronic properties. ${ }^{15}$ Neutral and electron-bound water trimers and pentamers are shown in Figure 1. Cyclic ring (3R) is the most stable. but it has very small VDE in comparison with the experimental value $(0.13$ $\mathrm{eV})$. The linear structure $3 \mathrm{~L}$ is higher in energy than the most stable neutral water trimer (3Neut: cyclic ring) and the $3 \mathrm{R}$ conformer. Thus, the $3 \mathrm{~L}$ conformer is considered to be the experimentally observed conformer. the intensity of which is very weak in the time-of-flight mass spectra.

The most stable electron-water pentamer was considered as a cyclic-ring structure $(5 R)$. However. $5 R$ conformer has two imaginary frequencies owing to the $C_{5}$ symmetry constraint at the B3LYP/6-311++G** (sp) and the MP2/aug$c c-p V D Z+(2 s 2 p / 2 s)$ levels of theory! ${ }^{15}$ The directions of these imaginary frequency modes are toward the neutral cyclic-ring structure. This confonmer is optimized into the structure similar to the lowest-energy neutral water pentamer at the MP2/aug-cc-pVDZ+(2s $2 p / 2 s)$ level without the symmetry constraint. $5 \mathrm{R}$ has very small $\mathrm{VDE}$ due to the very small dipole moment at its neutral state and the widely spread dangling $\mathrm{H}$ atoms. At the CCSD level, the relative stability of $5 \mathrm{Py}$ f conformer is enhanced in comparison with those of other conformers ${ }^{15}$ The red shifts for $\mathrm{OH}$ stretches are large for the double proton-acceptor ("aa"-ty'pe) water and also significant for a single proton-acceptor ("a"type) water. $5 \mathrm{Py}$ f. $5 \mathrm{R} 43 \mathrm{f}$ and $5 \mathrm{Y} 41^{*}$ are considerably stable conformers with one "aa"- or "a"-ty'pe water. The 5 Pyf conformer is the most stable with very large dipole moment at its neutral state. and has large VDE. The CCSD//MP2/ aug-cc-pVDZ+(2s $2 \mathrm{p} / 2 \mathrm{~s})$-predicted VDE of $5 \mathrm{Pyf}$ is $0.35 \mathrm{eV}$ which is close to the experimental value $(0.41 \mathrm{eV}){ }^{15}$ So. this $5 \mathrm{Pyf}$ conformer is considered as the observed structure for the electron-water pentamer.

Here. we discuss the dependency of the diffuse $(2 s 2 p / 2 s)$ basis sets at the MP2 level on the relative energies and VDEs of electron-water clusters (i.e. $3 \mathrm{R}$ and $3 \mathrm{~L}$ confomers). The other five diffuse basis sets $(2 \mathrm{~s} 2 \mathrm{p} / \mathrm{s})$. (2s $2 \mathrm{p})$. (2sp/s). (2sp) and (sp) were used instead of the diffuse ( $2 \mathrm{~s} 2 \mathrm{p} / 2 \mathrm{~s})$ basis set for the calculations. which resulted in the energy changes by $0.20,0.21,0.43,0.64$ and $3.76 \mathrm{kcal} / \mathrm{mol}$ for $3 \mathrm{R}$ and -0.01 . 0.09 .0 .00 .0 .16 and $0.80 \mathrm{kcal} / \mathrm{mol}$ for $3 \mathrm{~L}$ with respect to the $(2 \mathrm{~s} 2 \mathrm{p} / 2 \mathrm{~s})$ case. and the VDEs of $-0.01,-0.01,-0.02,-0.02$
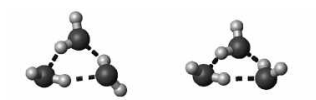

$3 \mathrm{R}$

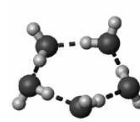

5 Neut

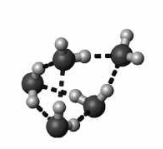

5 Pyf

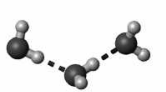

$3 \mathrm{~L}$

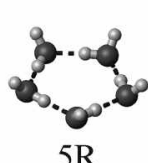

$5 \mathrm{R}$

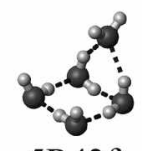

$5 \mathrm{R} 43 \mathrm{f}$

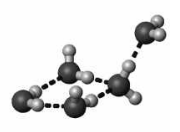

$5 \mathrm{Y} 41^{*}$
Figure 1. Structures of nentral and electron-bound water trimer and pentamer, $\mathrm{e}^{-}-\left(\mathrm{H}_{2} \mathrm{O}\right)_{3.5}$. and $-0.16 \mathrm{eV}$ for $3 \mathrm{R}$ and $0.11,0.11,0.11,0.11$ and $0.08 \mathrm{eV}$ for $3 \mathrm{~L}$. However. the energy changes of their neutral states are very small (all are within $0.02 \mathrm{kcal} / \mathrm{mol}$ ). The relative energies of $3 R$ and $3 L$ for the aug-cc-pVDZ $+(2 s 2 p / 2 s)$ $+\mathrm{X}(3 \mathrm{~s} 3 \mathrm{p})$ basis set with respect to ther aug-cc-pVDZ $+(2 \mathrm{~s} 2 \mathrm{p} /$ 2s) basis set are -0.06 and $-0.05 \mathrm{kcal} / \mathrm{mol}$, and those of their neutral states are -0.03 and $-0.05 \mathrm{kcal} / \mathrm{mol}$. while the change of VDEs are negligible. Thus. while the diffuse functions of oxygen atoms are very important for investigation of the electron-water clusters. the diffuse set $(2 \mathrm{~s} 2 \mathrm{p} / 2 \mathrm{~s})$ at the MP2 level shows almost converged realistic values for both energetic stability and VDE. On the other hand, the deletion of polarization functions $(\mathrm{d} / \mathrm{p})$ at the MP2 level enhances the relative stability for $3 \mathrm{~L}$ from 3.28 to $2.47 \mathrm{kcal} / \mathrm{mol}$, and decreases the relative stability for $3 \mathrm{R}$ from 0.73 to $0.92 \mathrm{kcal} /$ mol with respect to the neutral trimer. while their VDEs are slightly increased from 0.00 to $0.01 \mathrm{eV}$ for $3 \mathrm{R}$ and from 0.11 to $0.12 \mathrm{eV}$ for $3 \mathrm{~L}$. From these results the electron-binding states are weakly affected by diffused polarization functions. but the relative stabilities of the strong dipole-bound electron water clusters with respect to the corresponding neutral clusters are slightly enhanced. As a result. the use of suitable diffuse functions are more important than polarization functions to investigate the electron-water clusters.

The thenmodynamic properties of some interesting electronwater clusters (1-, 2- and 3-dimensional structures) have been studied using the MP2/aug-cc-pVDZ $+(2 \mathrm{~s} 2 \mathrm{p} / 2 \mathrm{~s})$ vibrational frequency calculations. The thenmodynamic effect for the relative stabilities of electron-water clusters is given in Figure 2. The 3-dimensional structures have more waterwater $\mathrm{HB}$ interactions than 1-dimensional or 2-dimensional conformers. Thus. at low temperatures 3 -dimensional structures are more stable than 1-or 2-dimensional ones. while at high temperatures 1- and 2-dimensional confonners are more favorable than 3-dimensional ones. The numbers of HBs in 3R. 3L, 5Pyf. 5R43f and 5Y41* are three. two seven. six. and five, respectively. This trend has also been noted in $\mathrm{H}$ bonded neutral. halide- and alkali metal-water clusters and

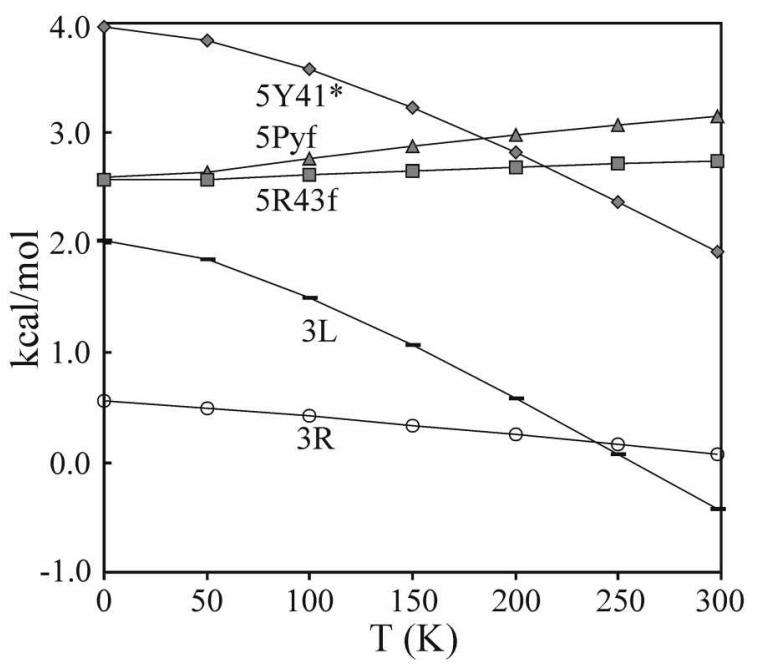

Figure 2. Themody namic stabilities of electron-water trimers and pentamers using MP2/aug-cc-pVDZ+(2s $2 p / 2 s)$ themodynamic enterties. 
weak electrostatic interaction systems ${ }^{516-15}$ The 1- or 2dimensional structures or less H-bonded structures are more favorable at high temperatures due to the entropy effect.

\section{Concluding Remarks}

The low-energy electron-water trimer is 1-dimensional structure, while the 3-dimensional structure is more stable for the electron-water pentamer. The thermodynamic stabilities of electron-water trimer and pentanier were discussed at the high level $a b$ initio levels of theory. The diffuse functions of oxygen atoms are very important and essential in order to obtain reliable relative stabilities and VDEs of small electronwater clusters. Using these reliable ab initio calculations. we find that in the cases of the electron-water trimer and pentamer, $3 \mathrm{R}$ and $5 \mathrm{Pyf} / 5 \mathrm{R} 43 \mathrm{f}$ are the most stable at low temperatures, while $3 \mathrm{~L}$ and $5 \mathrm{Y}+1$ are the most stable at room temperature. The lower dimensional conformers have less water-water $\mathrm{H}$-bonds than the higher dimensional conformers. Thus. as temperature increases, the linear or chainlike structures gain more stability than cyclic ones or 2-dimensional structures, and the latter ones again gain more stability than 3-dintensional ones.

Acknowledgement. This research was supported by KISTEP (CRI). MOST and partly by BK21. We would like to thank Professor K. S. Kim for helpful discussions.

\section{References}

1. (a) Haberland. H. Solvated Electron Chusters: Springer-Verlag: 1995: Vol. II. (b) Destrançois. C.: Carles. S.: Schermann. J. P. Chem. Rev 2000, 100, 3943. (c) Kim, K. S.: Tarakeshwar. P.: Lee. J. Y. Chem. Rev: 2000, 100.4145. (d) Tarakeshwar. P.: Kim. K. S. J. Mol Sintct 2002, 615, 227. (e) Tarakeshwar. P.: Lee, H. M.: Kim. K. S. Rariews of Wodem Otuntum Chemishy Sen. K. D. Ed.: World Scientific: Singapore, 2002: pp 1642-1683.

2. (a) Posev: L. A.: Johnson. M. A. J. Chent. Phws. 1988. 89. 4807. (b) Destrancois. C.: Khelifa. N.: Listi. A.: Schermann. J. P.: Eaton. J. G.: Bowen. K. H. J. Chent. Phns. 1991, 95, 7760) (c) Coe, I. V: Lee. G. H.: Eaton. J. G.: Arnold. S. T.: Sarkas. H. W.: Bowen. K. H.: Ludewigt. C. Harberland. H.: Worsnop. D. R. J. Chem. Phns. 1990. 92. 3980. (d) Campagnola. P. J: Cyr. D. M.: Johnson. M. A. Chem. Phs Lett. 1991. 181. 206. (e) Beyer. M. K.: Fox. B. S. Reinhard. B. M.: Bondybev. V. E. J. Chem. Phns. 2001, 115, 9288.

3. Blandamer. M. J.: Fox. M. F. Chem. Rev 1970. 70. 59.

4. Serxner D.: Dessent. C. E. H. Tolutson. M. A. J. Chem. Phns. 1996. 105.7231

5. (a) Baik. J.: Kim, I: Majundar. D.: Kim. K. S. J. Chen. Phns. 1999. 110.9116. (b) Majumdar. D.: Kim. J.: Kim. K. S. J. Chem. Phys. 2000, 112, 101. (c) Kim, I.: Lee, H. M, Sulh. S. B: Majundar. D.: Kim. K. S. J. Chem. Phs. 2000. 113. 5259. (d) Lee. H. M.: Kim. K. S. J. Chem. Phns. 2001. 114. 4461. (e) Lee. H. M.: Kim. D.: Kim. K. S. J. Chem. Phvs. 2002. 116, 5509.

6. Drukker. K.: de Leeuw. S. W. Chem. Pln's. Lett 1998. 291. 283.

7. Lehr. L.: Zanni. M. T.: Frischkon, C.: Weinkauf. R.: Neumark. D. M. Science 1999. 284. 635

8. Avotte, P.: Weddle. G. H.: Bailev, C. G.: Johnson, M. A.: Vila. F.: Jordan, K. D. J. Chent. Phns. 1999, H0.6268.

9. Bailey. C. G.: Kim. J.: Johnson. M. A. J. Phys. Ghem. 1996. 100. 16782 .

10. Ayotte. P.: Bailey. C. G.: Kim. J.: Johnson. M. A. J. Chem. Phns. 1998. $108,4.4$

11. Tauber. M. J.: Mathies. R. A. J. Am. Chem. Soc. 2003, 125. 1394

12. (a) Destrancois. C.: Khelifa. N.: Listi. A.: Schermann. J. P.: Eaton.
J. G.: Bowen, K. H. J. Chem. Plns. 1991. 95. 7760. (b) Destrancois C.: Baillon. B.: Schermant1. I. P.: Annold. S. T.: Hendricks. J. H.: Bowen, K. H. Ptns. Rev: Lett 1994, 72. 48. (c) Ayotte. P.: Jolnson, M. A. J. Chem. Phws. 1997. 106. 811. (d) Kiml. J.: Becker. I.: Cheshtrovshy. O.: Tohnson. M. A. Chem. Phys. Lett. 1998. 297. 90. (e) Weber, J. M.: Kim. J.; Woronowicz. E. A.; Weddle, G. H.: Becker. I.: Cheshnovshy. O.: Johnson. M. A. Chem. Plys. Lett. 2001. 339, 337 .

13. (a) Nowakowskaya. Y. V.: Stepanov. N. F. Chem. Phys. Lett 2001. 34+. 619. (b) Kulkarni. S. A.: Bartolotti. L. J., Pathak, R. K. J. Chent Phys 2000. 113. 2697. (c) Tachikawa. H. Lund. A.: Ogasawara. M. Con. J. Chem. 1993. 71. 118. (d) Kahn1. A. J. Chent. Phis $2003,118.1684$.

14. (a) Kim. T.: Park. T. M: Oh. K. S.: Lee. J. Y.: Lee. S.: Kim. K. S. $J$. Chent Phys 1997. 106. 10207. (b) Kim. K. S.; Lee, S.: Kim, J.: Lee. J. Y. J. Am. Chem. Soc. 1997. 119.9329. (c) Lee. S.: Kim. T.: Lee. S. J.: Kim. K. S. Plys. Ren Lett 1997. 79. 2038. (d) Kim. K. S.; Park. I; Lee, S.: Cho. K.; Lee, J. Y.: Kim. J.; Joannopoulos. J. D. Phus. Rev Lett 1996.76.956.

15. (a) Lee. H. M: Suh, S. B.: Kim. K. S. Bull Korem Chent Soc 2000. 21. 555 (b) Sult. S. B.: Lee. H. M.: Kiml. T.: Lee. T. Y.: Kim. K. S. J. Chem Phw 2000, 113,5273 . (c) Kim. J.: Lee. J. Y: Oh, K. S.: Park. J. M. Lee, S.; Kim, K. S. Phys. Ren A $1999,59$. R930. (d) Kim. T.: Suh. S. B.: Kim. K. S. J. Chem. Phos. 1999. 111. 10077 . (e) Lee. H. M.: Kim, K. S. J. Chem. Phvs. 2002. 117. 706. (f) Lee. H. M.: Lee. S.: Kim. K. S. J. Chem. Phis. (in press). (g) Lee. H. M:; Suh, S. B.: Kim. K. S. J. Chent Phys. $2003,118$. 9981 .

16. (a) Lee. H. M.: Suh. S. B.: Lee. J. Y.: Tarakeshwar. P.: Kim. K. S J. Chem. Phs 2000, 112, 9759, 2001, 11t, 3343, (b) Lee, H. M. Suh. S. B.: Kim. K. S. J. Chem. Phus. 2001. 114. 10749: 2001. 115. 7331. (c) Kim. K. S.: Mhin, B. J:- Choi, U.-S.: Lee. K. J. Chem. Plys. 1992.97. 6649. (d) Mhit1. B. J.: Lee. S. J.: Kim. K. S Phos Ren A 1993, 48, 3764. (e) Kim. J.; Majumdar. D: Lee. H. M; Kim. K. S. J. Chent Phys. 1999. 110,9128. (f) Kim. J.: Mhin. B. T.: Lee. S. J.: Kim. K. S. Chem Pln's Lett 1994. 219. 243. (g) Kim. J.: Lee, J. Y.: Lee. S.: Mhin, B. J Kim, K. S. J. Chem. Phns. 1995. 102. 310. (h) Kim. J.: Kim. K. S. J. Chem. Plns. 1998. 109 5886. (i) Kim, K. S.: Dupuis. M.: Lie. G. C.: Clementi, E. Chent. Phus. Lett. 1986. 131.451.

17. (a) Lee. S.: Cho. S. T.: Park. T. K.: Kim. H.-S.: Kim. K. S. Bull. Korean Chem. Soc. 1994. 15. 774. (b) Mhin, B. J.: Kim. J.: Kim. K. S. Chem. Phy Lett 1993. 216. 305. (c) Kiml. K. S.: Lee. S.: Mhin. B. J.: Cho. S. J.; Kim. J. Chent Phs Lett 1993. 216. 309. (d) Mhin. B. T.: Lee. S.: Cho. S. T.: Lee. K.: Kim. K. S. Chem. Phrs Lett 1992.197, 77, (e) Kim, J; Lee, S.; Cho. S. J.; Mhin, B J. Kim. K. S. J Chent Phys. 1995. 102,839. (t) Lee. S.; Kim, J.; Park. J. K.: Kim. K. S. J. Phus. Chem 1996. 100. 14329. (g) Lee. H. M.: Kim. J.: Lee, S.; Mhin, B. J.: Kim, K. S. J. Chent. Phws. 1999. 111. 3995 .

18. (a) Kim. K. S.; Lee. J. Y.: Choi. H. S.: Kim. J.: Jang. J. H. Chent Phys. Lett. 1997. 265. 497. (b) Tarakeshwar. P.: Lee. I. Y.: Kim. K S. J. Phus. Chem \& 1998. 102. 2253. (c) Tarakeshwar. P.: Kim. K. S.: Brutschy. B. J. Chent Phs. 2000. 112. 1769. (d) Lee, J. Y.: Kim. T.: Lee. H. M.: Tarakeshwar. P.: Kim. K. S. J. Chem. Phws. 2000. 113.6160. (e) Tarakeshwar. P. Kim. K. S.; Brutschy. B. J Chem. Phys. 2001. 114. 1295. (f) Tarakeshwar. P. Choi. H. S. Kim. K. S. J. Ant. Chem. Soc. 2001. 123,3323.

19. Manojkumar. T. K.: Choi, H. S.: Tarakeshwar. P.: Kim, K. S. J. Chem. Phus. 2003. 118. 8681

20. Frisch. M. J. Trucks, G. W: Schlegel, H. B. Gill, P. M. W: Johnson. B. G.: Robb. M. A.: Cheeseman. I. R.: Keith. T. A: Petersson, G. A.; Montgomery. J. A; Raghavachari. K.: AlLaham. M. A.: Zakrzewski. V. G.: Ortz. J. V.: Forseman. I. B.: Cioslowski. T.: Stefanov. B. B.: Nanayakikara. A.: Challacombe M.: Peng. C. Y.: Ayala. P. Y; Chen, W. Wong. M. W: Andres. J. L.: Replogle. E. S.: Gomperts. R.: Martin. R. L.: Fox. D. T.: Binkely, J. S.: Defrees. D. J.; Baker. J.; Stewart. J. P.: HeadGordon. M.: Gonzalez. C.: Pople. J. A. Gaussian 94. Rer. A: Gaussian. Inc.: Pittsburgh. PA. 1995. 